\title{
DEVELOPMENT AND CHARACTERIZATION OF ORO-DISPERSIBLE TABLETS OF METFORMIN HYDROCHLORIDE USING CAJANUS CAJAN STARCH AS A NATURAL SUPERDISINTEGRANT
}

\author{
SONIA DHIMAN, RITCHU BABBAR, THAKUR GURJEET SINGH*, SHIVANGI ANAND, ASHI MANNAN, SANDEEP \\ ARORA
}

Chitkara College of Pharmacy, Chitkara University, Punjab, 140401, India

Email: gurjeetthakur@gmail.com

Received: 17 Aug 2021, Revised and Accepted: 18 Nov 2021

\begin{abstract}
Objective: The aim of the research work was to explore the use of Cajanus cajan (Pigeon pea) polysaccharide as a superdisintegrant. The novel superdisintegrant has been evaluated for its action by incorporating it into orodispersible tablets of Metformin Hydrochloride.

Methods: Cajanus cajan starch was extracted from its seeds and superdisintegrant was developed by microwave modification of the extract. Various characterization tests such as gelatinization temperature, water absorption index, $\mathrm{pH}$, and viscosity were used to ide ntify the microwavemodified polysaccharide. The orodispersible tablets were made using a direct compression process employing varying concentrations of modified Cajanus cajan starch. Prepared tablets were tested for several pre and post-compression parameters and compared with a well-established synthetic superdisintegrant, sodium starch glycolate. The stability studies were conducted on an optimized formulation.
\end{abstract}

Results: Fourier transform infrared spectroscopy study showed that the drug had no interactions with the microwave-modified Cajanus cajan starch. SEM confirmed that Cajanus cajan starch granules exhibited intact granular structure in oval shapes and smooth surfaces. After microwave modification, the Cajanus cajan starch component lost its granular structure, which further led to the generation of surface pores and internal channels, causing overall swelling responsible for superdisintegrant activity. The optimized formulation (ODF5) containing 15 \% modified Cajanus cajan starch performed better in terms of wetting time (22.21 s), disintegration time (53.3 s), and in vitro drug release (92\%), as compared to formulation prepared by synthetic superdisintegrant (ODF1).

Conclusion: The present investigation concluded that modified Cajanus cajan starch has good potential as a superdisintegrant for formulating orodispersible tablets. Furthermore, modified Cajanus cajan starch is inexpensive, non-toxic and compatible in comparison with available synthetic superdisintegrants.

Keywords: Metformin hydrochloride, Cajanus cajan starch, Oro-dispersible Tablets, Sodium starch glycolate, Superdisintegrant

(C) 2022 The Authors. Published by Innovare Academic Sciences Pvt Ltd. This is an open access article under the CC BY license (https://creativecommons.org/licenses/by/4.0/) DOI: https://dx.doi.org/10.22159/ijap.2022v14i1.42904. Journal homepage: https://innovareacademics.in/journals/index.php/ijap

\section{INTRODUCTION}

The active pharmaceutical ingredient can be transported to the desired site of action safely and effectively through various drug delivery routes such as oral, parenteral, transdermal, and topical. Oral administration is the most common route of all these routes due to its benefits such as self-administration, high patient compliance, highdose drug administration, well-controlled scale-up procedures, and versatility in the dosage form design [1]. Solid dosage forms like tablets and capsules are administered orally and are the most popular dosage forms. But the major drawback with such dosage forms is the inconvenience in swallowing by the patients. To overcome this limitation, tablets that dissolve rapidly in the oral cavity have become quite common. Orodispersible tablets (ODTs) signify a rapidly evolving method of drug delivery with higher patient's compliance. For individuals that have swallowing problems, ODTs are very beneficial [2-4]. The disintegrate time of ODTs is within a minute and is suitable for patients with dysphasia $[5,6]$. ODTs have high bioavailability because as the saliva passes down the stomach, the absorption of some drugs from the mouth, pharynx, and esophagus follows. In both industry and academia, the benefits of ODTs are increasingly recognized [7]. Natural excipients are more beneficial than synthetic excipients because they are readily available, ecofriendly, biologically acceptable, and cost-efficient compared to imported synthetic products [8, 9]. Cajanus cajan (Pigeon Pea, Syn. Cajanus indicus) belongs to the family Fabaceae [10]. Its roots are most likely in Asia, from where it migrated to East Africa and then to the American continent through the slave trade [11]. It is currently being studied to treat ischemic necrosis of the caput femoris, aphtha, bedsores, and wound healing. For several years, it has been commonly used to treat diabetes, sores, skin irritations, hepatitis, measles, jaundice, dysentery, and several other diseases, remove bladder stones, and control the menstrual cycle [12]. A literature survey revealed that the $C$. cajan starch had not been used to date as a superdisintegrant, $C$. cajan was chosen for this research. The present study investigates the starch isolated from the seeds of $C$. cajan as a superdisintegrant in ODTs. The antihyperglycemic drug metformin hydrochloride belongs to the biguanide family of medicine, was used in the current study. Indeed, metformin HCL is a water-soluble drug and most preferred to be administered orally. Moreover, it is available in the form of immediate-release tablets and sustained-release tablets. The absorption of any water-soluble drug in the form of immediaterelease has also first undergone dissolution followed by absorption. Overall the process may take a minimum of $30 \mathrm{~min}$. In diabetic patients where immediate action of metformin is required, the orodispersible tablet of a freely soluble drug such as metformin will offer faster and higher absorption than its conventional forms. Thus the lag time between drug dissolution till absorption can be minimized. Metformin is currently the first-line therapy for type 2 diabetes [13]. Metformin hydrochloride has high water solubility and poor cell membrane permeability and belongs to the BCS type III drug [14]. The high dosage of metformin, on the other hand, necessitates a large tablet size, which decreases compliance among elderly patients due to swallowing difficulties [15]. There are no records in the literature that Cajanus cajan has been used as a superdisintegrant in the production of ODTs. This research aims to see if it's possible to make ODTs with $500 \mathrm{mg}$ of metformin $\mathrm{HCl}$ with an immediate-release profile, a fast onset of action, and substantial patient compliance. Furthermore, this research emphasizes the effects of an extract from Cajanus cajan seeds and its microwave-modified form on tablet properties.

\section{MATERIALS AND METHODS}

\section{Methodology}

Metformin Hydrochloride was obtained from Yarrow Chem. Pvt. Ltd., Mumbai. Sodium starch glycolate, Lactose monohydrate, 
Magnesium Stearate (Mgstearate), Talc, and sodium saccharin were procured from Loba Chemie Pvt. Ltd., Mumbai. Cajanus cajan seeds were purchased from a local vendor from Rajpura, Punjab and the voucher specimen of Cajanus cajan (seeds-voucher no. 0125), authenticated by a registered plant taxonomist and deposited at the department of botany, Sri Venkateshwara University, Tirupati, Andra Pradesh. All the chemicals and reagents were of analytical grade.

\section{Extraction of Cajanus cajan starch}

Cajanus cajan (pigeon pea) grains were washed several times with water before being grounded into a fine paste in a laboratory blender. The filtrate was permitted to settle after the slurry was strained through a fine muslin cloth. After 12-hour intervals, the supernatant was discarded, and the starch sediment was treated with distilled water. The starch sediment was spread out on trays and heated for two days at $60^{\circ} \mathrm{C}$ in a hot air oven. Mortar and pestle and a laboratory blender were used for crushing the dried mass, and a $60 \mathrm{~mm}$ sieve was used to sieve the fine powder. The attained starch was weighed and kept in an airtight container. The following equation was used to determine the yield [16]:

$$
\text { Yield }(\%)=\frac{\text { Weight of starch after drying }}{\text { Weight of seeds }} \times 100
$$

\section{Modification of Cajanus cajan polysaccharide by physical method}

The extracted polysaccharide was soaked in distilled water $(20 \%$ $\mathrm{w} / \mathrm{v}$ ) at room temperature for $24 \mathrm{~h}$. This suspension was modified in the microwave $(700 \mathrm{~W})$ for $3 \mathrm{~min}$. Since the microwave modification dried up the samples, an equivalent amount of water was used to remove the residual from the treated sample. Further, the starch powder was obtained by freeze-drying the sample [17].

\section{Characterization parameters of microwave modified Cajanus} cajan starch

Phytochemical tests for microwave modified cajanus cajan starch

Several phytochemical tests such as the biuret test, Mayer's and Molisch's tests were performed to identify alkaloids, carbohydrates, glycosides, proteins, and steroids [18].

\section{Gelatinization temperature}

To evaluate the gelation temperature, the starch powders were moistened with water and moved into capillary tubes. The temperature of gelling and the time from swelling to complete gelatinization were measured using a melting point apparatus [19].

\section{Determination of $\mathrm{pH}$}

A digital $\mathrm{pH}$ meter was used to assess the $\mathrm{pH}$ of $1 \%$ starch suspension [18]

\section{Viscosity}

Brookfield viscometer (Lab India Instruments Pvt. Ltd. Haryana, India) was used to determine the viscosity of $1 \%$ starch suspension [15].

\section{Water absorption index}

The starch sample was suspended in $10 \mathrm{ml}$ distilled water at $30{ }^{\circ} \mathrm{C}$ in a centrifuge tube, stirred for $30 \mathrm{~min}$, and centrifuged at $3000 \mathrm{rpm}$ for the next $10 \mathrm{~min}$ to determine the water absorption index. The gel formed was weighed after the supernatant was decanted. The gel weight per gram of dry sample was then used to measure the water absorption index [19-20].

$$
\text { Water absorption index }(\%)=\frac{\text { Bound water }(\mathrm{g})}{\text { Weight sample }(\mathrm{g})} \text { X100 }
$$

\section{Scanning electron microscopy}

Microstructures of the dry Cajanus cajan starch and microwave modified starch were visualized using an SEM system. Images were obtained using a high-sensitivity multi-mode backscatter electron (BSE) detector at $10 \mathrm{kV}$. SEM images were acquired at X 820 magnification.

\section{Formulation of orodispersible tablets}

Metformin hydrochloride ODTs were prepared with modified Cajanus cajan starch and sodium starch glycolate at different concentrations of 5 , $7.5,10$, and 15\% w/w (ODF 2-9) using a direct compression process. Tablets with formulation code ODF1 were prepared without any superdisintegrant. All the ingredients were filtered through a 60 mesh sieve. The powder blend was uniformly blended and compressed into $550 \mathrm{mg}$ tablets using 8-mm round flat punches on a rotary punching machine using a weighed quantity of each ingredient [21]. The composition of each formulation is given in table 1 .

\begin{tabular}{|c|c|c|c|c|c|c|c|c|c|}
\hline \multicolumn{10}{|l|}{ Formulations } \\
\hline Ingredients & ODF1 & ODF2 & ODF3 & ODF4 & ODF5 & ODF6 & ODF7 & ODF8 & ODF9 \\
\hline Metformin $\mathrm{HCl}$ & 500 & 500 & 500 & 500 & 500 & 500 & 500 & 500 & 500 \\
\hline Modified Cajanus cajan starch & -- & 10 & 15 & 20 & 30 & -- & -- & -- & -- \\
\hline Sodium starch glycolate & -- & -- & -- & -- & -- & 10 & 15 & 20 & 30 \\
\hline Lactose monohydrate & 45 & 35 & 30 & 25 & 15 & 45 & 30 & 25 & 15 \\
\hline Sodium saccharin & 1 & 1 & 1 & 1 & 1 & 1 & 1 & 1 & 1 \\
\hline Talc & 2 & 2 & 2 & 2 & 2 & 2 & 2 & 2 & 2 \\
\hline Magnesium stearate & 2 & 2 & 2 & 2 & 2 & 2 & 2 & 2 & 2 \\
\hline Total Weight (mg) & 550 & 550 & 550 & 550 & 550 & 550 & 550 & 550 & 550 \\
\hline
\end{tabular}

Table 1: Formulation of metformin hydrochloride orodispersible tablets

Total Weight (mg)

$$
\text { Tapped density }=\frac{\text { Weight of the powder }}{\text { tapped volume }}
$$

Evaluation of powder blend (Pre-compression parameters)

\section{Angle of repose}

The fixed funnel method was used to measure the angle of repose ( $A$ ) [22], which was determined using the following equation:

$$
\theta=\tan ^{-1}\left(\frac{\mathrm{h}}{\mathrm{r}}\right)
$$

Where $\theta$ stands for the angle of repose (in degrees), and $\mathrm{h}$ and $\mathrm{r}$ stand for height and radius for the heap in $\mathrm{cm}$, respectively.

\section{Determination of bulk and tapped densities}

The following formula was used to measure bulk density and tapped density [23]:

$$
\text { Bulk density }=\frac{\text { Weight of the powder }}{\text { bulk volume }}
$$

\section{Carr's compressibility index and hausner's ratio}

Carr's compressibility index and Hausner's ratio have become established as standard approaches for estimating powder flow characteristics due to their simplicity, utility, and ease of use [22]. Both the bulk density and tapped density of granules were calculated to assess the compressibility index and Hausner's ratio [24]:

$$
\text { Compressibility index }=\frac{\text { Tapped density }- \text { Bulk density }}{\text { Tapped density }} \text { X100 }
$$




\section{Evaluation of tablets (Post-compression parameters)}

\section{Tablet hardness}

The Monsanto hardness tester was used to assess the hardness [25] expressed in $\mathrm{kg} / \mathrm{cm}^{2}$.

\section{Tablet thickness}

Vernier caliper scale was used to measure the thickness, and a total of five measurements were taken [26].

\section{Weight variation}

Twenty tablets were taken at random and weighed individually for each prepared batch. Individual weights were compared to the average weight to determine the weight difference [27].

\section{Friability}

The tablets were measured and put in a Roche friabilator of the USP form. The friability was measured at $25 \mathrm{rpm}$ for $4 \mathrm{~min}$. The tablets were then dusted and measured again. There should be no more than a $1 \%$ weight loss. The following formula was used to measure the percentage weight loss (reliability) [24]:

$$
\text { Friability }=\frac{\text { Initial weight of the tablet }- \text { Final weight of the tablet }}{\text { Initial weight of the tablet }} \text { X100 }
$$

\section{Drug content uniformity}

Ten tablets were randomly weighed and crushed to a fine powder. A quantity of powder equivalent to $50 \mathrm{mg}$ of metformin hydrochloride was put in a $100 \mathrm{ml}$ volumetric flask and diluted with methanol. Then the solution was filtered and made up to $100 \mathrm{ml}$ using $\mathrm{pH} 6.8$ phosphate buffer. A UV-Visible spectrometer was used to determine the content of metformin hydrochloride by measuring the absorbance at $234 \mathrm{~nm}$. The standard calibration curve was used to assess the drug quantity [28].

\section{Wetting time}

To determine the wetting time of tablets, a piece of tissue paper folded twice was placed in a small Petri dish containing $6 \mathrm{ml} \mathrm{of} \mathrm{pH}$ 6.8 phosphate buffer and $1 \mathrm{ml}$ water containing amaranth (watersoluble dye) was added, a tablet was put on the paper, and the time for complete wetting was measured [29].

\section{Water absorption ratio (R)}

The weight of the tablet was measured before it was put in the Petri dish (Wb). A completely wetted tablet was extracted from the Petri dish and reweighed (Wa). The following equation was used to measure the water absorption ratio (R) [30]:

$$
\mathrm{R}=\frac{\mathrm{Wa}-\mathrm{Wb}}{\mathrm{Wb}} \times 100
$$

Where $W_{b}$ and $W_{a}$ denote the tablet weights before and after water absorption, respectively.

\section{In vitro disintegration time}

Disintegration is the method of breaking down a tablet into smaller particles. The dispersible formulation's in vitro disintegration period was calculated using a USP monograph for tablet disintegration research. The disintegration time was described as the amount of time needed for quick disintegration formulations to disintegrate until no solid residue is left entirely. As the immersion liquid, phosphate buffer pH 6.8 (simulated saliva fluid) was held at $37^{\circ} \pm 2$ ${ }^{\circ} \mathrm{C}$. A thermometer was used to continuously track the medium's temperature, and the disintegration time was recorded using a digital stopwatch. To ensure optimum precision, only one tablet was examined at a time. Tablet excipients and water was removed from the plastic disc and the basket rack by washing and drying it. Six tablets are tested from each batch, and the results are stated as mean, standard deviation. The tablet's in vitro disintegration time was measured according to IP specifications using a disintegration test apparatus [28].

\section{In vitro dissolution studies}

For in vitro dissolution study, $900 \mathrm{ml}$ of phosphate buffer (6.8 pH) as dissolution medium was used, maintained at $37{ }^{\circ} \pm 1{ }^{\circ} \mathrm{C}$ with a stirring speed of $50 \mathrm{rpm}$ for $60 \mathrm{~min}$. 1 tablet in each basket was placed in dissolution medium and at every $5 \mathrm{~min}, 10 \mathrm{ml}$ volume was withdrawn, maintaining sink condition. Absorbance was measured at $234 \mathrm{~nm}$ [31].

\section{Mathematical models for drug release}

The cumulative amount of metformin hydrochloride release from orodispersible tablets at different time intervals was fitted to zeroorder kinetics, first order kinetics, Higuchi model, Hixon-Crowel, and Korsmeyer-Peppas model to characterize the mechanism of drug release.

\section{Stability studies}

The formulation was evaluated for stability studies at $40 \pm 2{ }^{\circ} \mathrm{C} / 75 \%$ $\mathrm{RH}$ (ICH guidelines). The formulation was evaluated for a storage period of $3 \mathrm{mo}$, at monthly intervals, for various parameters [32].

\section{Data analysis}

The student's t-test was employed to analyze the one-way ANOVA results (Sigma Stat 3.5 Software). The difference below the probability level 0.05 was considered statistically significant.

\section{RESULTS AND DISCUSSION}

The starch extract obtained from Cajanus cajan (Pigeon pea) seeds was white to off-white colored powder (Yield $=32.4 \% \mathrm{w} / \mathrm{w}$ ). The $\mathrm{pH}$ of $1 \%$ Cajanus cajan polysaccharide suspension was found near to neutral. Water absorption capacity of the starch extract was determined to be $102.88 \%$. Table 2 summarises the results of the physicochemical characterization of the microwave-modified Cajanus cajan polysaccharide.

Table 2: Characterisation of physicochemical properties of microwave modified Cajanus cajan polysaccharide

\begin{tabular}{lll}
\hline S. No. & Parameter & Microwave modified Cajanus cajan \\
\hline 1. & Gelation temperature & $75^{\circ} \mathrm{C}$ \\
2. & pH & 6.9 \\
3. & Viscosity & $593 \mathrm{cP} \quad \%$ \\
4. & Water absorption capacity & $102.88 \quad \%$ \\
\hline
\end{tabular}

Natural super disintegrants include several natural substances such as mucilages, gums, and other natural substances that are more efficient at lower concentrations and have the higher disintegrating ability and mechanical power. When super disintegrants are exposed to water, they swell, hydrate, change volume or shape, and create pores in the tablet. Natural mucilage is favored to semisynthetic and synthetic mucilage since it is less costly, more easily accessible, and neither irritating nor toxic. Cajanus cajan starch has been found to have strong swelling properties, so it was examined as a superdisintegrant in metformin oro-dispersible tablets [17]. Metformin oro-dispersible tablets were made by direct compression with various modified Cajanus cajan starch concentrations as a natural superdisintegrant and were compared with a well-known synthetic superdisintegrant, sodium starch glycolate. The excipients were chosen based on preformulation tests, and a detailed literature review calculated their concentrations. As lactose monohydrate is directly compressible, it has been used as a diluent. To boost the flow properties of the powder mixture, talc was used as a glidant. Sodium saccharin was used as a sweetener [21, 28]. Magnesium stearate was used as an anti-adherent at a low dosage and was observed to have a detrimental effect on dissolution. It is evident 
from the infrared spectra in fig. 1 that the compound had no reactions with the microwave-modified Cajanus cajan starch. The key peak in the spectrum of the drug metformin hydrochloride does not vary substantially whether it is free or with polymer. The characteristic absorption stretch for $1688.48 \mathrm{~cm}^{-1}$ was observed in the FTIR spectra of pure Metformin hydrochloride, suggesting the presence of the $\mathrm{C}=\mathrm{N}$ (stretch) functional group. A plateau can be seen at $1254.14 \mathrm{~cm}^{-1}$, showing the presence of $\mathrm{C}-\mathrm{N}$ stretching. A peak is also visible at $1473.34 \mathrm{~cm}^{-1}$, showing the presence of $\mathrm{C}-\mathrm{H}$. (bend in plane). A peak at $732.97 \mathrm{~cm}^{-1}$, on the other hand, suggests the existence of the $\mathrm{N}-\mathrm{H}$ (rocking) functional group. All of the peaks were located in the FTIR spectra's fingerprint area. This demonstrates that the drug is compatible with the microwavemodified Cajanus cajan starch used in the formulations.

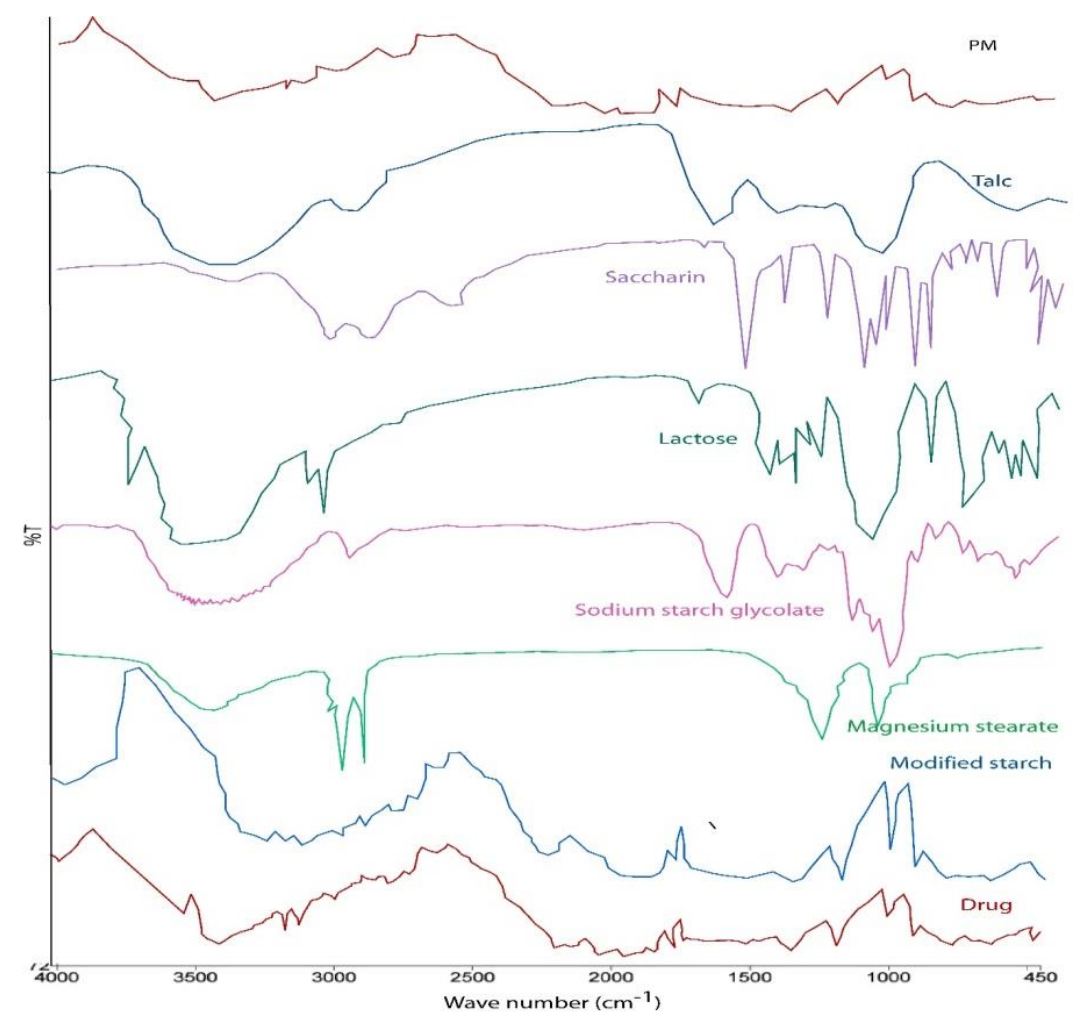

Fig. 1: FTIR spectrum of metformin hydrochloride (Drug), Microwave modified Cajanus cajan starch (Modified starch) with metformin hydrochloride, Raw materials (Magnesium stearate, sodium starch glycolate, lactose, saccharin, talc) and Physical mixture (PM)

In fig. 2(a, b), Cajanus cajan starch granules exhibited intact granular structure in oval shapes and smooth surfaces. After microwave modification, the Cajanus cajan starch component lost its granular structure, which had relatively bigger sizes, more scatches, and holes, as well as higher roughness on the surface, as shown in fig. 2(c). The process led to the generation of surface pores and internal channels in the microwaved modified Cajanus cajan starch, and also crystal formation could be seen, which is responsible for the overall swelling, wicking, and superdisintegrant activity of the microwave modified Cajanus cajan starch [21].
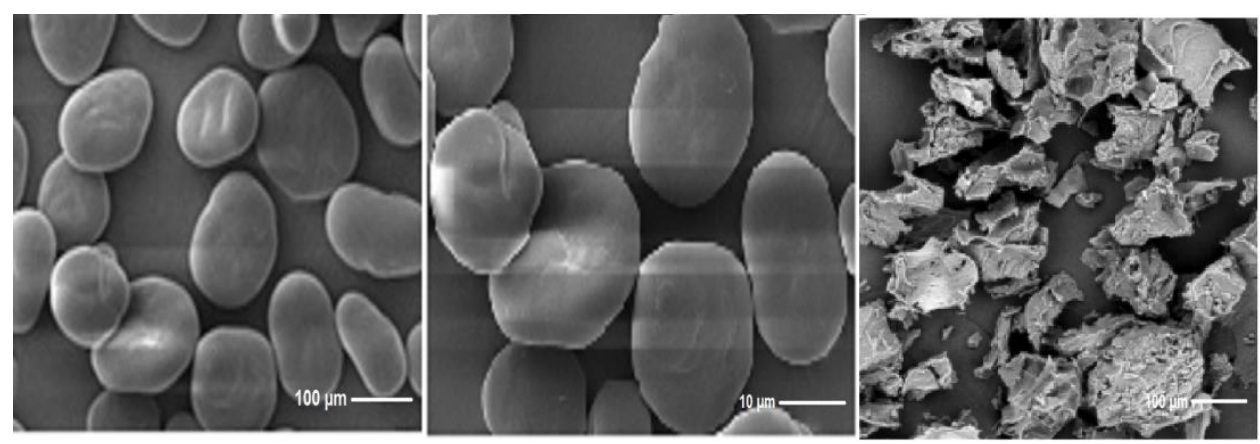

Fig. 2: SEM images of Cajanus cajan starch (a,b), microwave modified Cajanus cajan starch (c)

The percent compressibility for all formulations from ODF 2 to ODF9 lies within the range of 12.95 to 15.2 , indicating good compressibility of the powder mixture. For the same set of formulations, Hausner's ratios ranged from 1.17 to 1.27 , and the angle of repose values ranged from 24.8 to 28.8, which indicates a good flow of the drug, the results are in line with previous studies $[3,13,17,21,33]$. The pre-compression parameters are shown in fig. 3. 


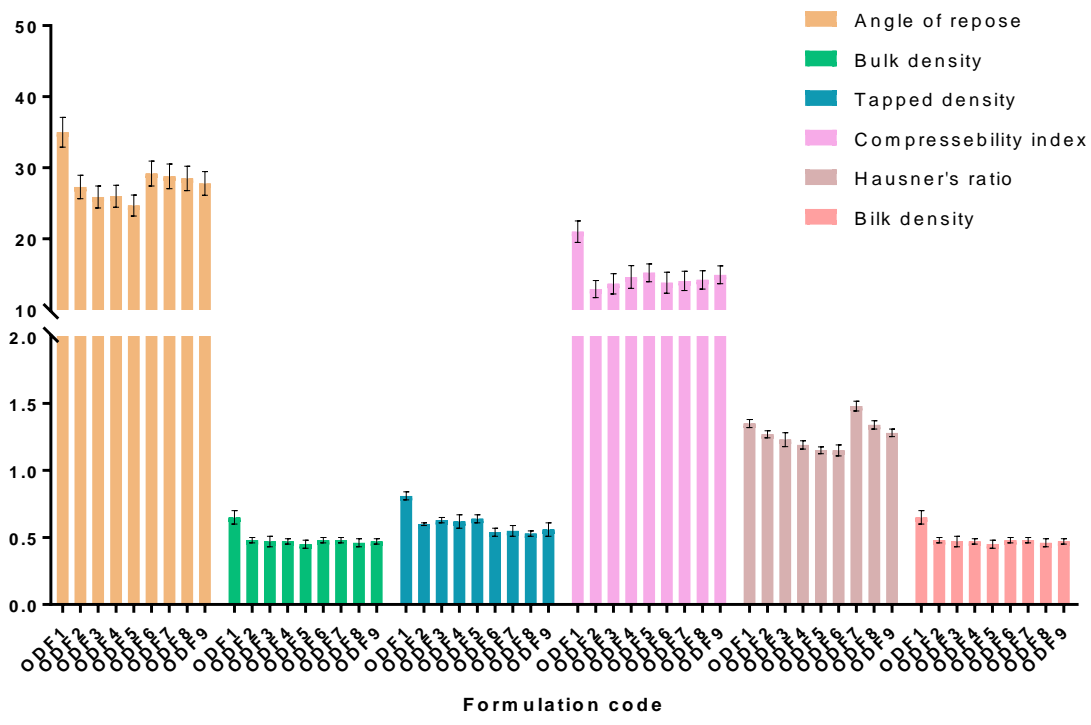

Fig. 3: Precompression parameters of powder blend, *Data are expressed as mean $\pm \operatorname{SD}(n=3)$

As mechanical integrity is essential in the formulation of oral disintegrating tablets, for the formulations ODF2 to ODF9, the hardness was calculated and preserved between 2.8 and $3.5 \mathrm{~kg} / \mathrm{cm}^{3}$. Since quick disintegrating tablets are not as hard as the standard tablets, they can be brittle and require individual packaging because of the lower compression used. It was noticed that all of the formulations were almost uniform in hardness in the particular process and had mechanical solid strength and hardness from the low standard deviation values; the results are inconsistent with previous studies [34-36] (fig. 4).

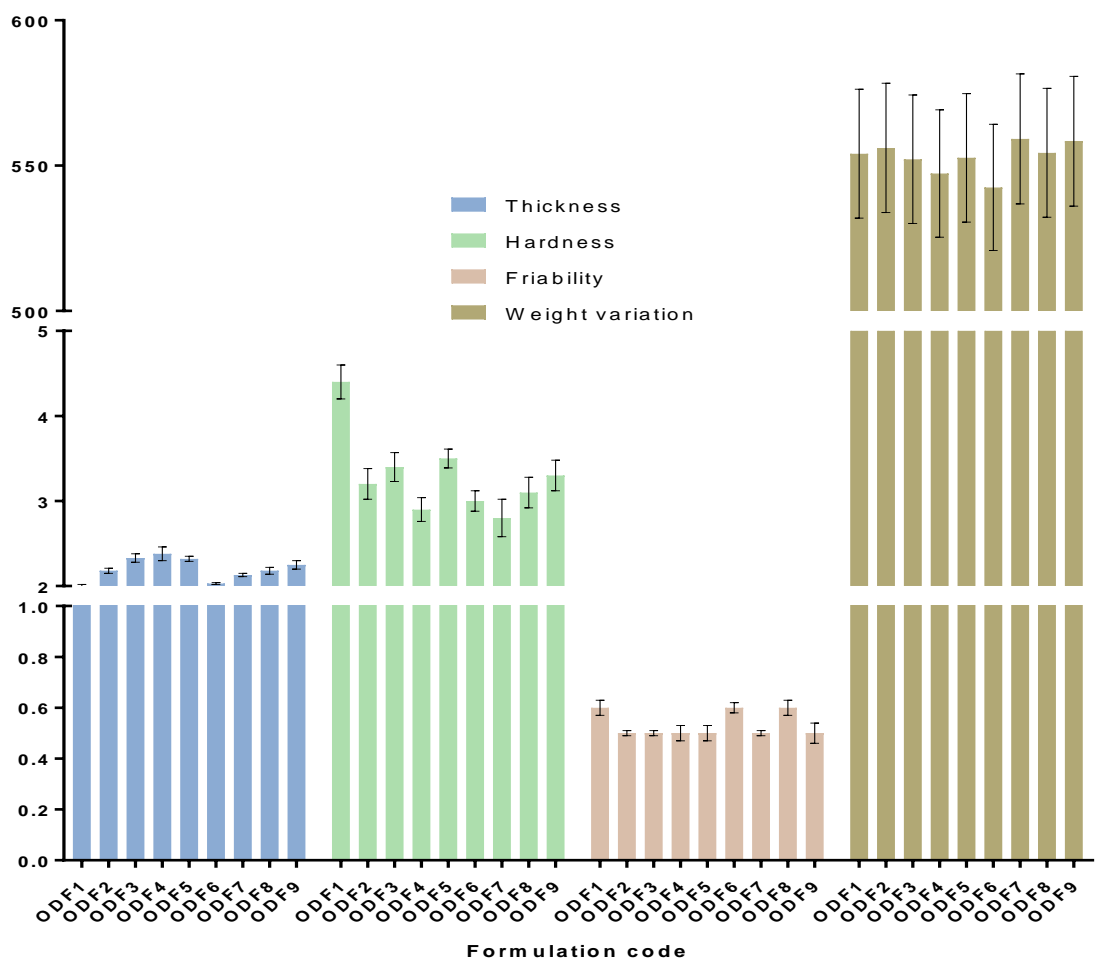

Fig. 4: Post compression parameters of metformin hydrochloride ODTs; ${ }^{\text {Data }}$ are expressed as mean \pm SD (n=3)

The tablets had a pharmaceutical content ranging from $94.13 \pm 0.5$ $\mathrm{mg}$ to $95.73 \pm 0.55 \mathrm{mg}$. This suggested that the medication quality was apparent in all formulations. The inner configuration of tablets is closely linked to wetting. The wetting time and water absorption ratio are essential measures of a disintegrant's tendency to swell in the presence of a small volume of water. The tablets containing sodium starch glycolate (ODF6 to ODF9) had a wetting time range of 72.3 to 141.3 s. The tablets contain different concentrations of microwave-modified Cajanus cajan starch (ODF2-ODF5) that had wetting times ranging from 32.39 to 22.21 s. The wetting time is 
inversely proportional to the concentration of superdisintegrant; it decreases as the concentration of superdisintegrant is increased, and directly proportional to the disintegration time of the formulation in the oral cavity is increased as the wetting time is increased, results obtained are in line with previously published data $[24,28]$ (fig. 5). The water absorption ratio values of formulations with microwave modified Cajanus cajan extract, ODF2ODF5, were found in the range of 50.73 to 52.57 . The water absorption ratio of the formulations with sodium starch glycolate, ODF6-ODF9, was 43.12 to 49.27 . This indicated that the water absorption ratio of the microwave-modified Cajanus cajan was better than sodium starch glycolate (fig. 5). Compared to formulations with sodium starch glycolate, the in vitro drug release rate from formulations with microwave-modified Cajanus cajan was faster. Fig. 6 illustrates the in vitro drug release profiles of the formulations ODF1 to ODF9. The composition of the disintegrant agent, which causes the tablet to split up into smaller fragments as it comes into contact with physiological fluid, is linked to the disintegration period, which is influenced by the tablet's hardness. The in vitro disintegration time of formulations containing microwave-modified Cajanus cajan (ODF2ODF5) ranges from $137.1 \pm 0.24 \mathrm{~s}$ to $53.3 \pm 0.57 \mathrm{~s}$; results are in line with previous studies $[17,21,28]$.

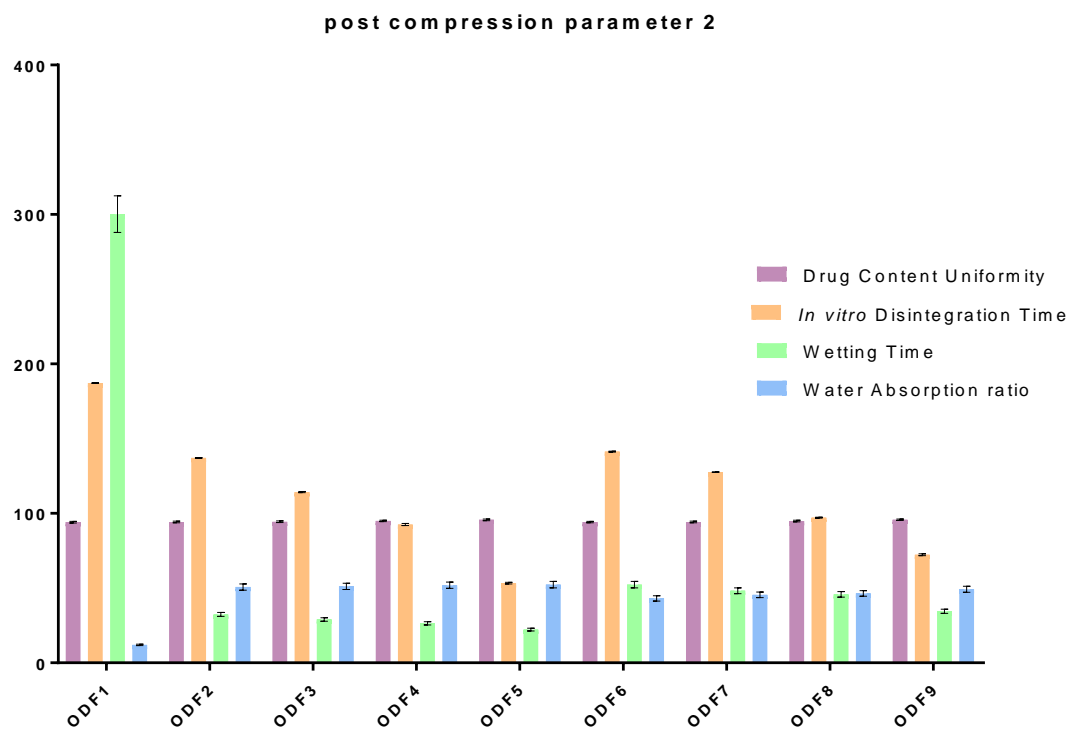

Fig. 5: Post compression parameters of metformin hydrochloride $0 D T s,{ }^{*}$ Data are expressed as mean \pm SD $(n=3$ )

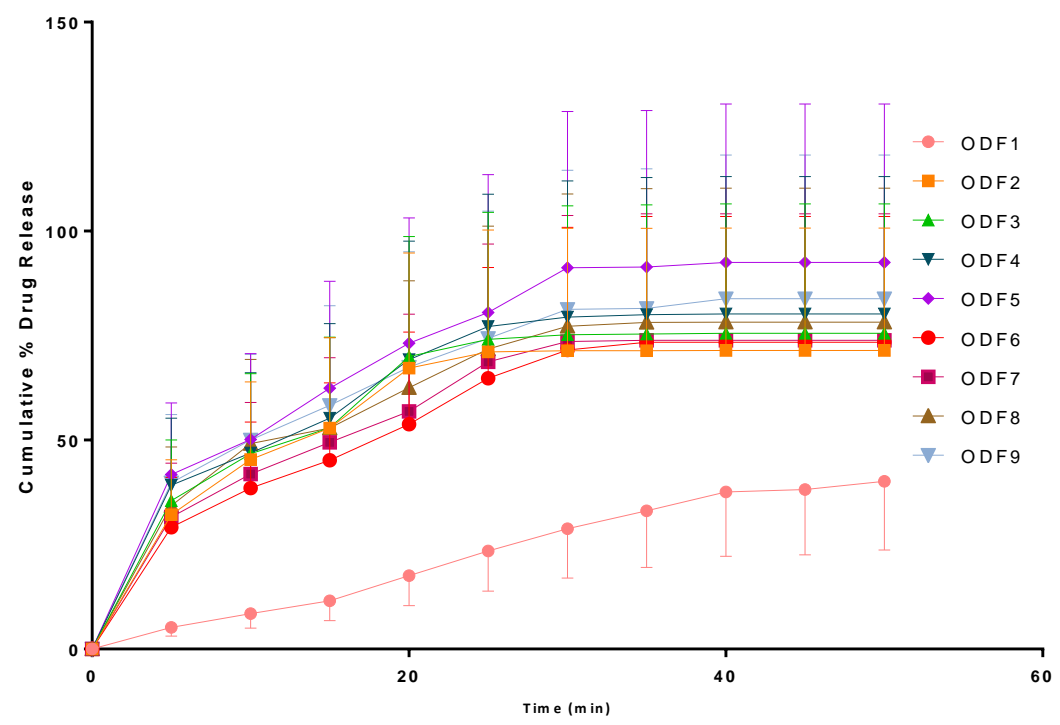

Fig. 6: In vitro drug release profile for formulations ODF1 to ODF9, $*$ Data are expressed as mean \pm SD (n=3)

To determine the release model that best describes the drug release mechanism, in vitro release data of Metformin hydrochloride orodispersible tablets was fitted into zero-order, first-order, Higuchi, Korsmeyer Peppas, and Hixon Crowell release models. The release pattern of a specific mechanism was based on the correlation coefficient $\left(R^{2}\right)$ for the parameters studied $[33,34]$. The highest correlation coefficient is preferred for selecting the mechanism of release. The release kinetics of optimized formulation ODF5 in different models is illustrated in table 3 . 
Table 3: Drug release kinetics of model fitting in optimized metformin hydrochloride oro-dispersible tablets

\begin{tabular}{llll}
\hline Model & $\mathbf{R}^{\mathbf{2}}$ & Slope & \\
\hline Zero Order & 0.7885 & 7.8965 & 22.465 \\
First Order & 0.952 & 0.121 & 2.0325 \\
Higuchi & 0.9183 & 0.6166 & 0.8679 \\
Hixon-Crowell & 0.907 & 0.271 & 4.4631 \\
Korsmeyer-peppas & 0.8535 & 1.1745 & 44.53 \\
\hline
\end{tabular}
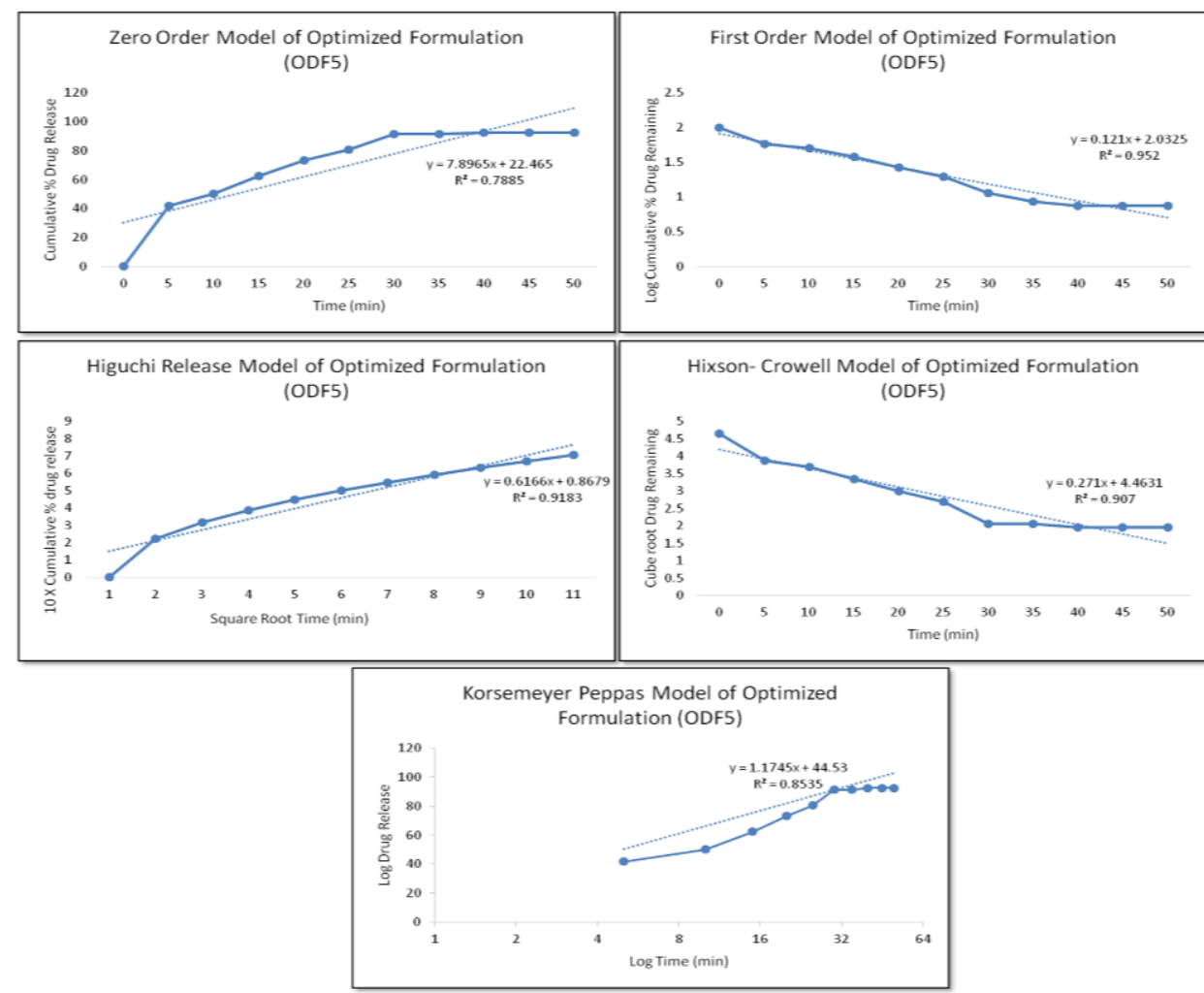

Fig. 7: Zero-order model, First-order model, Higuchi release model, Hixson-crowell model, Korsmeyer peppas model for optimize formulation (ODF5)

It was found that the drug was released by first-order kinetics, which was indicated by the maximum $\mathrm{R}^{2}$ value of 0.952 (fig. 7).
Stability studies of optimized formulation (ODF5) carried out for three months are mentioned in table 4.

Table 4: Stability studies of optimized formulation (ODF5)

\begin{tabular}{|c|c|c|c|c|}
\hline Specification & Initial & $30 \mathrm{D}$ & $60 \mathrm{D}$ & $90 \mathrm{D}$ \\
\hline Average weight (mg) & $552.7 \pm 1.50$ & $552.3 \pm 1.53$ & $552.1 \pm 1.54$ & $552.1 \pm 1.53$ \\
\hline Hardness $\left(\mathrm{kg} / \mathrm{cm}^{2}\right)$ & $3.5 \pm 0.11$ & $3.5 \pm 0.17$ & $3.2 \pm 0.14$ & $3.2 \pm 0.16$ \\
\hline Drug content $(\%)$ & $95.69 \pm 0.5$ & $95.33 \pm 0.4$ & $95.18 \pm 0.6$ & $94.78 \pm 0.3$ \\
\hline Disintegration time (s) & $53.3 \pm 0.57$ & $53.7 \pm 0.56$ & $54.2 \pm 0.53$ & $54.2 \pm 0.52$ \\
\hline$f_{2}$ value & 90.5 & 88 & 86.4 & 82.1 \\
\hline
\end{tabular}

${ }^{*}$ Data are expressed as mean \pm SD $(n=3)$

From the overall parameters, formulation ODF5 was considered the optimized batch; thus, it was subjected to stability studies. The values of various parameters and the $f_{2}$ value observed during the $90 \mathrm{~d}$ stability studies are shown in table 4 . Storage of orodispersible tablets at $40 \pm 2{ }^{\circ} \mathrm{C} / 75 \%$ RH of the selected formula (ODF5) shows no significant changes.

\section{CONCLUSION}

According to this report, Cajanus cajan starch can be used as a superdisintegrant to formulate oro-dispersible tablets. Cajanus cajan starch can be used instead of commercially available super disintegrants because it is less costly than synthetic superdisintegrants, is non-toxic, stable, and simple to produce. Patient compliance, fast onset of action, improved bioavailability, low side effects, and good stability are all advantages of the prepared tablets, making them popular as a dosage form for the treatment of Diabetes mellitus Type II.

\section{ACKNOWLEDGMENT}

The authors are grateful to the Chitkara College of Pharmacy, Chitkara University, Rajpura, Patiala, Punjab, India, for providing the necessary facilities to carry out the research work. 


\section{FUNDING}

Nil

\section{AUTHORS CONTRIBUTIONS}

All authors have contributed equally.

\section{CONFLICTS OF INTERESTS}

There are no conflicts of interest.

\section{REFERENCES}

1. Dhiman S, Singh TG, Dharmila PP. Mouth dissolving tablets: as a potential drug delivery system-a review. Int J Pharm Sci Rev Res. 2011;11:85-94.

2. Midha K, Nagpal M, Aggarwal G, Gurjeet Singh TG. Development of dispersible self-microemulsifying tablet of atorvastatin. Pharm Methods. 2015;6(1):09-25. doi: 10.5530/phm.2015.6.2.

3. Mahesparan VA, Bin Abd Razak FS, Ming LC, Uddin AH, Sarker MZI, Bin LK. Comparison of disintegrant-addition methods on the compounding of orodispersible tablets. Int J Pharm Compd. 2020;24(2):148-55. PMID 32196477.

4. Mushtaq M, Fazal N, Niaz A. Formulation and evaluation of fastdisintegrating tablets of flurbiprofen and metoclopramide. J Pharm Innov. 2021;16(3):419-38. doi: 10.1007/s12247-02009455-z.

5. Ghosh D, Singh SK, Khursheed R, Pandey NK, Kumar B, Kumar R, Kumari Y, Kaur G, Clarisse A, Awasthi A, Gulati M, Jain SK, Porwal O, Bayrakdar E, Sheet M, Gowthamarajan K, Gupta S, Corrie L, Gunjal P, Gupta RK, Singh TG, Sinha S. Impact of solidification on micromeritic properties and dissolution rate of self-nanoemulsifying delivery system loaded with docosahexaenoic acid. Drug Dev Ind Pharm. 2020;46(4):597605. doi: 10.1080/03639045.2020.1742143, PMID 32162980.

6. Wasilewska K, Ciosek Skibinska P, Lenik J, Srcic S, Basa A, Winnicka K. Utilization of ethylcellulose microparticles with Rupatadine fumarate in designing orodispersible minitablets with taste masking effect. Materials (Basel). 2020;13(12):2715. doi: 10.3390/ma13122715, PMID 32549213.

7. Swarnalatha N, Maravajhala V. Formulation, in vitro, and in vivo evaluation of taste-masked oral disintegrating tablets of fexofenadine hydrochloride using semisynthetic and natural super disintegrants. Int J Appl Pharm. 2021:99-108. doi: 10.22159/ijap.2021v13i5.41558.

8. Iurian S, Dinte E, Iuga C, Bogdan C, Spiridon I, Barbu Tudoran L, Bodoki A, Tomuţă I, Leucuţa SE. The pharmaceutical applications of a biopolymer isolated from Trigonella foenumgraecum seeds: focus on the freeze-dried matrix-forming capacity. Saudi Pharm J. 2017;25(8):1217-25. doi: 10.1016/j.jsps.2017.09.006, PMID 29204071.

9. Sankhyan A, Pawar PK. Metformin loaded non-ionic surfactant vesicles: optimization of formulation, effect of process variables and characterization. Daru. 2013;21(1):7. doi: 10.1186/2008-2231-21-7, PMID 23351604.

10. Wu N, Fu K, Fu YJ, Zu YG, Chang FR, Chen YH, Liu XL, Kong Y, Liu W, Gu CB. Antioxidant activities of extracts and main components of pigeonpea [Cajanus cajan (L.) Millsp.] leaves. Molecules. 2009;14(3):1032-43. 10.3390/molecules14031032, PMID 19305357.

11. Kumar H, Bajpai VK, Dubey RC, Maheshwari DK, Kang SC. Wilt disease management and enhancement of growth and yield of cajanus cajan (L) var. manak by bacterial combinations amended with chemical fertilizer. Crop Prot. 2010;29(6):591-8. doi: 10.1016/j.cropro.2010.01.002.

12. Zu YG, Liu XL, Fu YJ, Wu N, Kong Y, Wink M. Chemical composition of the SFE-CO extracts from cajanus cajan (L.) huth and their antimicrobial activity in vitro and in vivo. Phytomedicine. 2010;17(14):1095-101. 10.1016/j.phymed.2010.04.005, PMID 20576412.

13. Gulsun $\mathrm{T}$, Akdag $\mathrm{Y}$, Izat $\mathrm{N}$, Cetin $\mathrm{M}$, Oner $\mathrm{L}$, Sahin $\mathrm{S}$. Development and characterization of metformin hydrochloride- and glyburide-containing orally disintegrating tablets. Pharm Dev Technol. 2020;25(8):999-1009. doi: 10.1080/10837450.2020.1772290, PMID 32431206.

14. Thakur G, Singh A, Singh I. Chitosan-montmorillonite polymer composites: formulation and evaluation of sustained-release tablets of aceclofenac. Sci Pharm. 2015;84(4):603-17. doi: 10.3390/scipharm84040603, PMID 28656939.

15. Vanbillemont B, Everaert H, De Beer T. New advances in the characterization of lyophilised orally disintegrating tablets. Int J Pharm. 2020;579:119153. doi: 10.1016/j.ijpharm.2020.119153, PMID 32084575.

16. Dhaliwal SK, Talukdar A, Gautam A, Sharma P, Sharma V, Kaushik P. Developments and prospects in imperative underexploited vegetable legumes breeding: a review. Int J Mol Sci. 2020;21(24). doi: 10.3390/ijms21249615, PMID 33348635.

17. Sun X, Ohanenye IC, Ahmed T, Udenigwe CC. Microwave treatment increased protein digestibility of pigeon pea (Cajanus cajan) flour: elucidation of underlying mechanisms. Food Chem. 2020;329:127196. doi: 10.1016/j.foodchem.2020.127196, PMID 32516712 .

18. Ogoda Onah J, Akubue PI, Okide GB. The kinetics of reversal of pre-sickled erythrocytes by the aqueous extract of cajanus cajan seeds. Phytother Res. 2002;16(8):748-50. doi: 10.1002/ptr.1026, PMID 12458479.

19. Maninder K, Sandhu KS, Singh N. Comparative study of the functional, thermal and pasting properties of flours from different field pea (Pisum sativum L.) and pigeon pea (Cajanus cajan L.) cultivars. Food Chem. 2007;104(1):259-67. doi: 10.1016/j.foodchem.2006.11.037.

20. Hoover R, Swamidas G, Vasanthan T. Studies on the physicochemical properties of native, defatted, and heatmoisture treated pigeon pea (Cajanus cajan L) starch. Carbohydr Res. 1993;246(1):185-203. doi: 10.1016/00086215(93)84032-2.

21. Pawar H, Varkhade C, Jadhav P, Mehra K. Development and evaluation of orodispersible tablets using a natural polysaccharide isolated from cassia tora seeds. Integr Med Res. 2014;3(2):91-8. doi: 10.1016/j.imr.2014.03.002, PMID 28664083.

22. Sivadasan D, Sultan MH, Madkhali O, Javed S, Jabeen A. Formulation and in vitro evaluation of orodispersible tablets of fexofenadine hydrochloride. Trop J Pharm Res. 2020;19(5):919-25. doi: 10.4314/tjpr.v19i5.2.

23. Rao AHOP, Kumar RS, Kandukuri S, Ramya M. Optimization of starch glycolate as novel super disintegrant in the formulation of glipizide fast dissolving tablets through 23factorial design. Int J Appl Pharm. 2021;2021:244-51.

24. Gajera KG, Raval AG. Formulation and evaluation of orodispersible tablets of paliperidone. IJPBA. 2019;7(2):175-8. doi: 10.32553/ijpba.v7i2.116.

25. Subhranshu P. Formulation and evaluation of metoprolol succinate orodispersible tablets using directly compressible coprocessed excipient of Moringa Gum. AJP. 2020;14(1):1-8.

26. Vijayanand P, Patil JS, Reddy MV. Formulation and comparative pharmacokinetic evaluation of orodispersible tablets and films of nebivolol hydrochloride. J Pharmaceutical Investigation. 2015;45(2):237-47. doi: 10.1007/s40005-014-0169-5.

27. Dhiman S, Singh TG. Design and optimization of floating matrix tablets of famotidine by central composite design. Asian J Pharm Clin Res. 2012;5:45-9.

28. Kumari N, Sharma R. An immediate-release tablet of carvedilol with natural superdisintegrants fenugreek seed mucilage and synthetic superdisintegrants. Asian J Pharm Technol. 2020;10(3):156-64. doi: 10.5958/2231-5713.2020.00027.6.

29. Bala R, Sharma S, Ikgptu. Formulation and evaluation of fast dissolving tablet of aprepitant by using natural and synthetic superdisintegrants. Int J Appl Pharm. 2020:64-71. doi: 10.22159/ijap.2020v12i1.35222.

30. Huanbutta K, Yunsir A, Sriamornsak P, Sangnim T. Development and in vitro/in vivo evaluation of tamarind seed gum-based oral disintegrating tablets after fabrication by freeze-drying. J Drug Deliv Sci Technol. 2019;54. doi: 10.1016/j.jddst.2019.101298.

31. Tashan E, Karakucuk A, Celebi N. Development of nanocrystal ziprasidone orally disintegrating tablets: optimization by using design of experiment and in vitro evaluation. AAPS PharmSciTech. 2020;21(3):115. doi: 10.1208/s12249-02001653-9, PMID 32296987.

32. Mazzo DJ. The ICH stability guideline. In: International stability testing. CRC Press; 2020. p. 1-13. 
33. Singh K, Sharma S. Development and characterization of orodispersible tablets of propranolol hydrochloride using calcium cross-linked Cassia fistula gum and cross carmellose sodium. Int J App Pharm. 2020:160-9. doi: 10.22159/ijap.2020v12i4.37955.

34. Panda SA, Hemalatha N, Shankar PU, Baratam SR. Formulation and evaluation of orodispersible tablets (ODTS) of diclofenac sodium by using superdisintegrant from natural origin. Int J App Pharm. 2019;11(6):190-7. doi: 10.22159/ ijap.2019v11i6.33480.

35. Oliveira LJ, Veiga A, Stofella NCF, Cunha AC, da Graça T Toledo M, Andreazza IF, Murakami FSOliveira LJ, Veiga A, Stofella NCF,
Cunha AC, da Graça T Toledo M, Andreazza IF, Murakami FS. Development and evaluation of orodispersible tablets containing ketoprofen. Curr Drug Deliv. 2020;17(4):348-60. doi: 10.2174/1567201817666200317122807., PMID: 32183668.

36. Manda P, Popescu C, Juluri A, Janga K, Kakulamarri PR, Narishetty S, Narasimha Murthy S, Repka MA. Micronized zaleplon delivery via orodispersible film and orodispersible tablets. AAPS PharmSciTech. 2018;19(3):1358-66. doi: 10.1208/s12249-017-0924-9. Epub 2018 Jan 19. PMID: 29352403. 